\title{
Bidding into the Red: A Model of Post-Auction Bankruptcy
}

\author{
SIMON BOARD*
}

\begin{abstract}
This paper investigates auctions where bidders have limited liability. First, we analyze bidding behavior under different auction formats, showing that the second-price auction induces higher prices, higher bankruptcy rates, and lower utilities than the firstprice auction. Second, we show that the cost of bankruptcy critically affects the seller's preference over the choice of auction. If bankruptcy is very costly, the seller prefers the first-price auction over the second-price auction. Alternatively, if the bankrupt assets are resold among the losers of the initial auction, the seller prefers the second-price auction.
\end{abstract}

AUCTIONS ARE BECOMING AN EVER MORE POPULAR way to allocate important, largescale property rights. A major concern in such large auctions is that agents may bid aggressively, anticipating that they can declare bankruptcy if the good is worth less than expected. This problem is frequently encountered when selling large assets. For example, ITV Digital went bankrupt after aggressively bidding for the right to broadcast Football League games, owing $£ 178 m$. Default is also common in procurement auctions. For example, Connex's rail franchise for southeast England was taken over by the government after it demanded extra subsidies to continue operating. These examples illustrate the prevalence of post-auction bankruptcy and provide a cautionary tale: As auction mechanisms become an increasingly useful tool for both government and industry, the possibility of default should be taken into account when designing the auction.

The basic structure of the paper follows the seminal work of Waehrer (1995), Rhodes-Kropf and Viswanathan (2000), and Zheng (2001). The seller first auctions a good among a number of bidders. After the auction, uncertainty is revealed and the winning bidder decides whether to declare bankruptcy or pay his bid. ${ }^{1}$

The contribution of this paper is twofold. First, we analyze the effect of different auction formats on bidding behavior. We find that the second-price auction (SPA) induces higher prices, higher bankruptcy rates, and lower utilities than the first-price auction (FPA). This analysis is important because the choice of

\footnotetext{
*Board is from the Department of Economics, University of Toronto. I am indebted to Alan Beggs, Jeremy Bulow, and Paul Klemperer for their guidance, and to an anonymous referee whose comments greatly improved the paper. I would also like to thank Pat Bajari, Eiichiro Kazumori, Jon Levin, John McMillan, Rob McMillan, Meg Meyer, Paul Milgrom, Andreas Park, José Quintero, Margaret Stevens, and Bob Wilson.

${ }^{1}$ The auctioneer is female, while the bidders are male.
} 
auction format is the primary mechanism through which the seller can affect revenue. Moreover, such a choice can have substantial effects: In some simple numerical examples, we show that moving from the FPA to the SPA raises prices by $20 \%$ but also increases the probability of bankruptcy by $5 \%$ (see Table II in Section III).

Our second contribution is to examine the effect of bankruptcy costs on the seller's revenue. While previous studies focus on the case of costless bankruptcy, we show that the seller's view of bankruptcy and her preference over the auction format depend critically on the post-bankruptcy recovery rate. The analysis focuses on three scenarios.

(1) Under the large-recovery scenario, the seller inherits any bankrupt assets with relatively little efficiency loss. A special case of the large-recovery scenario is the full-recovery model, where bankruptcy is costless. For example, when the British government took over Connex's rail franchise, many of the assets and employees stayed in place with little change in performance. ${ }^{2}$

(2) Under the small-recovery scenario, the seller inherits any bankrupt assets, valuing them significantly less than the winning bidder. One can think of the bankrupt firm being run by the seller, albeit less efficiently, or the assets being used for another purpose altogether. For example, the ITV Digital bankruptcy led to large welfare losses: Customers fled the digital operator at a rate of $7 \%$ per month, hundreds of employees were laid off, and many football teams were forced into administration. ${ }^{3}$

(3) Under the resale-recovery scenario, we endogenize the recovery rate by assuming that any bankrupt assets are resold among the losing bidders from the initial auction. For example, soon after the 1996 C-block spectrum auction, the largest bidder, NextWave, declared bankruptcy. In response, the FCC reclaimed and resold the licenses NextWave purchased in the auction. ${ }^{4}$

Our revenue results can be summarized as follows. Under large recovery, the seller prefers auctions with high prices and a high probability of bankruptcy, such as the SPA. Conversely, under small recovery, the seller prefers auctions with a low probability of bankruptcy, such as the FPA. Under resale recovery, the seller's preferences are more subtle: She prefers auctions with low bankruptcy rates ceteris paribus, but prefers the SPA over the FPA. Even

\footnotetext{
${ }^{2}$ See the Financial Times, "Connex's $£ 58 \mathrm{~m}$ aid adds to rail fears" (12/12/02), and "Authority's patience finally reached the end of the line" (28/06/03).

${ }^{3}$ See the Financial Times, "Turmoil and ITV Digital owners throw in towel" (28/03/02), "ITV Digital to cut 900 jobs as customers quit" (20/04/02), and "Football clubs slide deeper into cash crisis after losing court battle over ITV Digital” (02/08/02).

${ }^{4}$ In fact, the FCC was so keen to reauction these licenses that they did so twice. The FCC initially resold the licenses in 2001. The Supreme Court then decided this repossession contravened federal bankruptcy law and ordered the FCC to return the spectrum. However, in 2005, the FCC received a proportion of these licenses back in a settlement with NextWave and reauctioned them successfully. For background on this case, see Zheng (2001). Also, see Wall Street Journal, "NextWave Regains Control of Wireless Licenses" (28/01/03), "NextWave-FCC Deal Frees Up Firm's Idle Wireless Spectrum" (21/04/04), and "FCC Begins Auction of Spectrum Licenses" (27/01/05).
} 
though bankruptcy occurs more frequently under the SPA, bankruptcy tends to occur when the efficiency loss is relatively small. Taken together, these results illustrate the importance of the recovery rate for auction design and provide guidance to sellers who may be concerned about post-auction bankruptcy.

\section{Outline of the Paper}

As a benchmark against which to compare the models of costly bankruptcy, Section III first re-examines the full-recovery model of Waehrer (1995) and Rhodes-Kropf and Viswanathan (2000), where bankrupt assets are turned over to the seller with no efficiency loss.

Section III.A analyzes the auction from the bidders' perspective, deriving two main results. First, we show that the SPA induces higher expected prices than the FPA. Intuitively, limited liability caps the downside loss, leading bidders to become more aggressive. Since bids are higher under the SPA than under the FPA, the introduction of limited liability leads to a larger reduction in downside loss and a larger increase in aggressiveness. Because prices are higher, the SPA also induces higher bankruptcy rates and lower utilities than the FPA.

Second, we show that the introduction of limited liability increases bidding aggressiveness so much that bidders' utilities are lower than under unlimited liability, despite the option value of bankruptcy. That is, all bidders would prefer to be in an unlimited liability world than a limited liability world. The intuition for this Insolvency Effect is that agents earn information rents when they are awarded the good and stay solvent. Thus, any decrease in solvency rates-such as that introduced by limited liability-lowers utility.

Section III.B looks at the auction from the seller's perspective under the fullrecovery assumption. Revenue equals social welfare minus the bidders' information rents. Bankruptcy has no effect on welfare because of full recovery, but reduces rents via the Insolvency Effect. Thus, the seller becomes bankruptcy loving in that revenue is higher under limited liability than under unlimited liability. As a result, the seller prefers the SPA, in which the probability of bankruptcy is relatively high, over the FPA, in which the probability of bankruptcy is relatively low. The full-recovery assumption also yields a very stark result: Revenue is maximized by a stochastic auction that induces bankruptcy with probability $1-\epsilon$. Since this kind of random auction is not particularly prevalent, it seems important to understand the role of the fullrecovery assumption.

Section IV analyzes costly bankruptcy, where the recovery rate is an exogenous function of the winning bidder's valuation and the post-auction shock. In this model, one can think of the seller taking over the winning bidder's company in the case of bankruptcy. First, we consider the large-recovery case, where the efficiency loss of bankruptcy is relatively small and is outweighed by the Insolvency Effect. For example, after a toll road goes bankrupt, the new owner may be able to employ the same operating systems with little loss in productivity. As under full recovery, the seller is bankruptcy loving and prefers the SPA over the FPA. Second, we consider the small-recovery case, where the efficiency 
Table I

\section{Revenue and Post-bankruptcy Recovery}

This table summarizes the main revenue results of the paper under different recovery rates. The second and third columns describe the effect of bankruptcy on revenue. The final column compares revenue under the first-price auction (FPA) and under the second-price auction (SPA).

\begin{tabular}{lllc}
\hline & $\begin{array}{c}\text { View of } \\
\text { Bankruptcy }\end{array}$ & $\begin{array}{c}\text { Limited vs. Unlimited } \\
\text { Liability }\end{array}$ & FPA vs. SPA \\
\hline Large recovery & Bankruptcy loving & Limited liability & SPA \\
Small recovery & Bankruptcy averse & Unlimited liability & FPA \\
Resale recovery & Bankruptcy averse & Unlimited liability & SPA \\
\hline
\end{tabular}

loss of bankruptcy is sufficiently large that it outweighs the Insolvency Effect. For example, the bankruptcy of a school building contractor may cause a lot of disruption and result in the loss of much project-specific knowledge. In this situation, the seller is bankruptcy averse and prefers the FPA over the SPA.

Section $\mathrm{V}$ endogenizes the post-bankruptcy recovery rate by assuming that any bankrupt assets are resold among the losing bidders from the initial auction. When the seller uses sequential FPAs, the potential for resale raises the opportunity cost of winning the good in the initial auction and reduces bidding aggressiveness. When the seller uses sequential SPAs, there is a second effect: A bidder may bid more aggressively in order to bankrupt their opponent. Under this resale-recovery scenario, the seller is bankruptcy averse in that revenue is higher under unlimited liability than under limited liability. However, in a numerical example, we show that the seller prefers the SPA over the FPA, despite bankruptcy occurring more frequently under the former. Intuitively, under the SPA, bankruptcy tends to occur when the second highest valuation is high and therefore the efficiency loss from bankruptcy is small.

Table I broadly summarizes the revenue results from Sections IV and V.

Section VI applies the revenue results to a number of practical problems. First, we analyze the spinoff problem, whereby parent companies create poor spinoffs to bid on their behalf. By creating a poor subsidiary, a bidder commits himself to be aggressive, increasing his utility from the auction. However, if all bidders create subsidiaries then they are all worse off, via the Insolvency Effect. Bidders are thus caught in a prisoner's dilemma: Creating a spinoff is individually profitable, but the spinoff equilibrium exhibits lower utilities than if spinoffs were banned. Moreover, under small recovery, the creation of spinoffs lowers the seller's revenue. Indeed, we argue that the failure to appreciate the spinoff problem led to the ITV Digital debacle mentioned in the Introduction and could have been prevented with minimum wealth requirements or parent company guarantees.

We also examine the effect of allowing the post-auction shock to be contractible. If the seller can make the payment depending on the shock, via a cost-plus contract, this would benefit all bidders and, under small recovery, also benefit the seller. Similarly, all bidders would be better off if they committed to 
purchase insurance. However, insured bidders are less aggressive and are put at a competitive disadvantage. As in the spinoff problem, this leads to a prisoner's dilemma: Every bidder would be better off if they all acquired insurance, but no bidder has an individual incentive to do so.

\section{A. Related Literature}

The main precursors to this paper are the models of Waehrer (1995), RhodesKropf and Viswanathan (2000), and Zheng (2001).

Waehrer (1995) considers the effect of default in SPAs and, under additive separability, FPAs. In his model, a defaulting bidder must make a payment to the seller; this payment plays the same role as wealth in our model. From the bidder's side, Waehrer shows that bids increase as their wealth declines. ${ }^{5}$ From the seller's side, Waehrer considers a number of post-default renegotiation situations. In the "strong seller" case, the seller gets all the surplus from the renegotiation, as in our full-recovery case, and revenue is decreasing in the bidders' wealth (see Section III.B).

Rhodes-Kropf and Viswanathan (2000) study bidding using a variety of securities. Of most relevance to our paper, they compare cash auctions (i.e., unlimited liability auctions) and debt auctions (i.e., limited liability auctions). Under the assumption of full recovery, they show that limited liability raises more revenue than unlimited liability in the context of an FPA (see Section III.B). Rhodes-Kropf and Viswanathan also discuss a number of broader issues, including renegotiation and the design of security auctions. For more on the latter topic, see DeMarzo, Kremer and Skrzypacz (2005).

Zheng (2001) studies the effect of bankruptcy and credit constraints in an FPA. His paper considers a seller who accepts only cash bids, and bidders that have access to credit markets. Zheng focuses on the effect of wealth asymmetries, assuming that all bidders have the same valuation of the good, and considers two counteracting forces. When credit is cheap, poor bidders bid more aggressively than wealthy ones because they can easily declare bankruptcy; when credit is expensive, wealthy bidders can afford to be more aggressive. These forces are further explored by Rhodes-Kropf and Viswanathan (2005), who suppose bidders have private information about both their wealth and their valuations, and seek to finance their bids through the market. Rhodes-Kropf and Viswanathan consider both debt and equity markets, and examine how different types of financing affect the relationship between wealth and bids.

The results on post-bankruptcy resale are most closely related to the work of Milgrom and Weber (2000) on sequential auctions. In our auction, bidder $i$ benefits from raising the price of bidder $j$. This feature is shared by takeover auctions with toeholds (Burkart (1995), Bulow, Huang and Klemperer (1999)), partnership problems (Cramton, Gibbons and Klemperer (1987)), and charity auctions (Goeree et al. (2005)).

\footnotetext{
${ }^{5}$ A version of this result was first derived by Hansen and Lott (1991) in the context of a two-signal two-value common value first-price auction.
} 
Throughout this paper, a crucial variable of interest is the post-bankruptcy recovery rate. This feature is also shared by the incomplete contracting literature, which finds that an increase in the recovery rate tends to increase the level of sustainable debt, lower the interest rate, and increase the debt maturity (e.g., Hart and Moore (1994, 1998)). While the majority of this literature considers an exogenous recovery rate, Shleifer and Vishny (1992) explore these bankruptcy costs by allowing "insiders" to have higher values than "outsiders." They point out that when bankruptcy hits one inside firm, other insiders will probably have financial difficulties and will thus be unable to purchase the assets in any fire sale. We endogenize the recovery rate by reselling any bankrupt assets among the losing bidders from the initial auction but, in contrast to Shleifer and Vishny, do not allow for sequential bankruptcies.

\section{Basic Model}

Consider $N$ risk-neutral bidders, each with wealth $w$, who compete for a single indivisible good. Before the auction, each agent $i$ observes a private signal $\theta_{i} \in[\underline{\theta}, \bar{\theta}]$. These signals are distributed independently and identically with distribution function $F\left(\theta_{i}\right)$ and density $F\left(\theta_{i}\right)$, where we allow $\bar{\theta}=\infty$. Let $\theta:=\left(\theta_{1}, \ldots, \theta_{N}\right)$ and $\theta_{-i}:=\left(\theta_{1}, \ldots \theta_{i-1}, \theta_{i+1}, \ldots \theta_{N}\right)$. Denote the $k^{\text {th }}$ highest signal by $\theta_{(k)}$.

After the auction, a shock $s \in[s, \bar{s}]$, distributed independently of $\theta$, is privately observed by the winning bidder. Agent $i$ 's post-auction valuation is $v\left(\theta_{i}, s\right)$, where $v\left(\theta_{i}, s\right)$ is increasing in both arguments and $\partial v\left(\theta_{i}, s\right) / \partial \theta_{i}$ is uniformly bounded $\left(\forall \theta_{i}\right)(\forall s)$. Denote the induced distribution of valuations by $G\left(v \mid \theta_{i}\right)$. The value function $v\left(\theta_{i}, s\right)$ is increasing in $\theta_{i}$, so $G\left(v \mid \theta_{i}\right)$ is decreasing in $\theta_{i}$. Sometimes it will be useful to strengthen this assumption and suppose that a larger $\theta_{i}$ increases the distribution of $v\left(\theta_{i}, s\right)$ in the hazard rate order

Assumption (HR): Preferences satisfy the hazard rate order if

$$
\frac{1-G\left(v \mid \theta_{i}\right)}{g\left(v \mid \theta_{i}\right)}
$$

is increasing in $\theta_{i} \cdot{ }^{6}$

In Sections III and IV, we consider auctions where any bankrupt assets return to the seller and each bidder has only one chance to win the good (i.e., without post-bankruptcy resale). An auction is then defined by a triple $\left\langle P_{i}, y_{i}, z_{i}\right\rangle$. For any bidder $i, P_{i}$ is the probability that $i$ wins the good, $y_{i}$ is $i$ 's payment if he wins the auction, and $z_{i}$ is $i$ 's payment if he loses. These payments can depend upon the bids of all agents, and include the FPA, SPA, and all-pay auction (APA) as special cases. ${ }^{7}$

\footnotetext{
${ }^{6}(\mathrm{HR})$ is implied by the affiliation of $v_{i}$ and $\theta_{i}$. In the additive case, where $v\left(\theta_{i}, s\right)=\theta_{i}-s,(\mathrm{HR})$ says that the distribution of $s$ obeys the familiar monotone hazard assumption.

${ }^{7}$ Since the post-auction shock $s$ is privately observed by the winning bidder, these payments are not allowed to depend upon the shock. That is, the seller is restricted to debt contracts. See the discussion in Section IV.D.
} 
Under limited liability, a bidder can declare bankruptcy if his utility is negative. If bidder $i$ wins, his utility is

$$
u\left(\theta_{i}, w-y_{i}\right)=E_{s}\left[\max \left\{v\left(\theta_{i}, s\right)+w-y_{i}, 0\right\}\right],
$$

where $E_{s}$ is the expectation over the post-auction shock $s$. If bidder $i$ loses, his utility is $\max \left\{w-z_{i}, 0\right\}$. In comparison, under unlimited liability, bidder $i$ 's utility, conditional on winning, is

$$
u^{\mathrm{UL}}\left(\theta_{i}, w-y_{i}\right)=E_{s}\left[v\left(\theta_{i}, s\right)+w-y_{i}\right] .
$$

The seller's revenue depends upon the financial viability of the winning bidder, $i$. If bidder $i$ remains solvent, then the seller collects the promised payment $y_{i}$. If bidder $i$ goes bankrupt, then the seller, as the senior debt holder, obtains the assets of the firm. These assets, $w+\bar{v}$, consist of the bidder's wealth and some additional return from the bankrupt asset. In Section III, we follow the literature in assuming full recovery, $\bar{v}=v\left(\theta_{i}, s\right)$, where bankruptcy results in no social loss. In Section IV, we generalize this analysis by allowing for costly bankruptcy, $\bar{v} \leq v\left(\theta_{i}, s\right)$.

\section{Auctions with Full Recovery}

\section{A. Bidding Behavior}

There are three main results about bidding behavior that will prove useful for the analysis of revenue in subsequent sections.

1. The FPA yields lower prices, higher utilities, and higher solvency rates than the SPA. This is established in Section III.A.1.

2. For any standard auction (defined below), an increase in the equilibrium probability of bankruptcy lowers bidders' utilities (the Insolvency Effect). Consequently, moving from unlimited liability to limited liability reduces utilities and raises prices. This is established in Section III.A.2.

3. In FPA and SPAs, a symmetric increase in wealth reduces bids, increases solvency rates, and, via the Insolvency Effect, increases bidders' utility net of their wealth. Intuitively, a wealthier agent has more to lose from bankruptcy and bids less aggressively. This result is proved by Waehrer (1995, proposition 3).

\section{A.1. First-Price and Second-Price Auctions}

First, consider the SPA. ${ }^{8}$ In the symmetric Nash equilibrium of the limited liability auction, agent $i$ is indifferent between winning and losing, conditional on just winning. Hence, agent $i$ 's bid $B\left(\theta_{i}\right)$ is given by

$$
E_{s}\left[\max \left\{v\left(\theta_{i}, s\right)+w-B\left(\theta_{i}\right), 0\right\}\right]=w .
$$

\footnotetext{
${ }^{8}$ In Sections III and IV, all the SPA results also apply to the English auction.
} 
In financial terms, one can view the good as a call option that costs $w$ on an asset worth $v\left(\theta_{i}, s\right)+w$. The second-price bid is then the highest strike price such that the bidder is willing to purchase the option. Under unlimited liability, $i$ bids according to $B^{\mathrm{UL}}\left(\theta_{i}\right)=E_{s}\left[v\left(\theta_{i}, s\right)\right]$. It is straightforward to verify that $B\left(\theta_{i}\right)$ is increasing in $\theta_{i}$ and decreasing in wealth. When wealth is sufficiently high, bankruptcy is never an option, so $\lim _{w \rightarrow \infty} B\left(\theta_{i}\right)=B^{\mathrm{UL}}\left(\theta_{i}\right)$. When wealth is sufficiently low, bidders have nothing to lose and bid as if they are the luckiest person on the earth, $\lim _{w \rightarrow 0} B\left(\theta_{i}\right)=v\left(\theta_{i}, \bar{s}\right)$.

Turning to the FPA, we focus on the increasing symmetric pure bidding strategy, $b\left(\theta_{i}\right)$. As we show in Appendix A, (HR) implies that such a strategy exists. If bidder $i$ pretends to be type $\hat{\theta}_{i}$, he obtains

$$
E_{s}\left[\max \left\{v\left(\theta_{i}, s\right)+w-b\left(\hat{\theta}_{i}\right), 0\right\}-w\right] F^{N-1}\left(\hat{\theta}_{i}\right)+w .
$$

Taking the first-order condition with respect to $\hat{\theta}_{i}$ and evaluating at $\hat{\theta}_{i}=\theta_{i}$, agent $i$ 's bidding function is given by the differential equation

$$
\begin{aligned}
& b^{\prime}\left(\theta_{i}\right) E_{s}\left[\mathbf{1}_{v\left(\theta_{i}, s\right)+w-b\left(\theta_{i}\right) \geq 0}\right] \boldsymbol{F}\left(\theta_{i}\right)^{N-1} \\
& \quad=E_{s}\left[\max \left\{v\left(\theta_{i}, s\right)+w-b\left(\theta_{i}\right), 0\right\}-w\right] \frac{d}{d \theta_{i}} F\left(\theta_{i}\right)^{N-1}
\end{aligned}
$$

with the boundary condition $b(\underline{\theta})=B(\underline{\theta})$. When a bidder pretends to be a higher type they pay more when solvent (the left side of (3)) but have a larger chance of winning (the right side of (3)).

A bidder's interim utility equals his utility conditional on his own signal, taking expectations over other agents' signals. The price is the payment due to a seller before anyone declares bankruptcy, while the expected interim price is the expectation of the price, conditional on the winner's signal.

Proposition 1: Suppose (HR) holds. Under limited liability:

(a) Expected interim prices are lower under the FPA than the SPA.

(b) Expected interim utilities are higher under the FPA than the SPA.

(c) If $G\left(v \mid \theta_{i}\right)$ is convex in $v$, the interim probability of solvency is higher under the FPA than the SPA. ${ }^{9}$

Proof: See the Appendix.

Part (a) says that the SPA leads to higher prices than the FPA. Intuitively, the introduction of limited liability caps the downside loss, which leads bidding to become more aggressive. Under the SPA, agents bid the most they are willing to pay for the good. Since this bid frequently exceeds the value of the good, the introduction of limited liability leads to a large reduction in downside loss and a large increase in aggressiveness. Under the FPA, agents must pay their bid and so bid less than their willingness to pay, $b\left(\theta_{i}\right) \leq B\left(\theta_{i}\right)$. The introduction

\footnotetext{
${ }^{9}$ If $v\left(\theta_{i}, s\right)=\theta_{i}-s$ and $s \sim U[\underline{s}, \bar{s}]$, then the concavity assumption is satisfied for all relevant valuations if $\tilde{y}_{i} \leq \theta_{i}-\underline{s}+w$ with probability one, which holds for the SPA and TPA.
} 


\section{Table II}

\section{Comparing First-Price and Second-Price Auctions}

This table compares the first- and second-price auctions under exogenous recovery (i.e., with no post-bankruptcy resale). This example uses the uniform-additive model where $i$ 's signal is $\theta_{i} \sim U[0,1]$, the post-auction shock is $s \sim U[0,1]$ and $i$ 's valuation is $v\left(\theta_{i}, s\right)=\theta_{i}-s$. The first column describes the number of bidders and their wealth. The second column shows the expected probability of solvency. The third and final column gives the expected price in the auction, prior to any bankruptcy decision.

\begin{tabular}{|c|c|c|c|c|c|}
\hline \multicolumn{2}{|c|}{ Parameters } & \multicolumn{2}{|c|}{ Prob. Solvency } & \multicolumn{2}{|c|}{ Expected Price $\times 100$} \\
\hline No. of Bidders & Wealth & $\operatorname{FPA}(\%)$ & $\operatorname{SPA}(\%)$ & FPA & SPA \\
\hline 3 & $1 / 10$ & 72.7 & 68.7 & 12.3 & 15.3 \\
\hline 3 & $1 / 100$ & 45.3 & 39.1 & 30.7 & 36.9 \\
\hline 10 & $1 / 100$ & 25.3 & 23.2 & 66.6 & 68.7 \\
\hline
\end{tabular}

of limited liability therefore leads to a relatively small reduction in downside loss and a small increase in aggressiveness. In financial terms, agents are bidding on a call option that is more in the money under an FPA. Hence, the effect of introducing bankruptcy is less pronounced. Parts (b) and (c) then say that utilities and solvency rates are both lower under the SPA since prices are higher. ${ }^{10}$

Table II illustrates the magnitude of the effects in Proposition 1 in the uniform-additive model, where $v\left(\theta_{i}, s\right)=\theta_{i}-s, \theta_{i} \sim U[0,1]$ and $s \sim U[0,1]$. When there are three bidders and wealth is relatively low, moving from the FPA to the SPA makes bankruptcy around 5\% more likely, while increasing prices by $20 \%$. Table II also shows that bidding becomes more aggressive, and bankruptcy occurs more frequently, as bidders become poorer and as the number of bidders increases. ${ }^{11}$

\section{A.2. Limited and Unlimited Liability}

We now compare limited and unlimited liability across a wide range of auctions $\left\langle P_{i}, y_{i}, z_{i}\right\rangle$. This will be particularly useful when analyzing revenue. Consider the direct revelation mechanism where each bidder $i$ of type $\theta_{i}$ pretends to be type $\hat{\theta}_{i}$. The seller awards the good to $i$ with probability $P_{i}\left(\hat{\theta}_{i}, \hat{\theta}_{-i}\right)$, the winner

${ }^{10}$ For example, consider the uniform-additive model, where $v\left(\theta_{i}, s\right)=\theta_{i}-s, s \sim U[0,1]$, and $w=$ 0 . Under the SPA, limited liability bidders bid as if there is no shock $B\left(\theta_{i}\right)=\theta_{i}$. Under the FPA, the payoff for a limited liability bidder who may go bankrupt is $(1 / 2)\left(\theta_{i}-b\left(\hat{\theta}_{i}\right)\right)^{2} F^{N-1}\left(\hat{\theta}_{i}\right)$. Hence, bidding is identical to that of an unlimited liability bidder facing $(N-1) / 2$ competitors and no shock. Under the SPA, the introduction of limited liability increases bids by one-half for all types of agents. Under the FPA, type $\underline{\theta}$ also increases his bid by one-half, while higher types raise their bids by less than one-half.

${ }^{11}$ When there are many bidders, bankruptcy may occur with very high probability. If $\lim _{\theta_{i} \rightarrow \bar{\theta}}(1-$ $\left.F\left(\theta_{i}\right)\right) / f\left(\theta_{i}\right)=0$, then the probability the winner declares bankruptcy converges to one as $N \rightarrow \infty$ and $w \rightarrow 0$ (Board (2005)). 
pays $y_{i}\left(\hat{\theta}_{i}, \hat{\theta}_{-i}\right)$, and the losers pay $z_{i}\left(\hat{\theta}_{i}, \hat{\theta}_{-i}\right)$. After the auction, the shock $s$ is revealed and the winning bidder chooses whether to declare bankruptcy, denoted by $\sigma_{i}=0$, or stay solvent, denoted by $\sigma_{i}=1$. By the revelation principle, we can limit ourselves to mechanisms in which truth telling is a Bayesian Nash equilibrium. If agents $-i$ report truthfully, agent $i$ then chooses $\hat{\theta}_{i}$ to maximize his utility,

$$
\begin{aligned}
U_{i}\left(\theta_{i}, \hat{\theta}_{i}\right)= & E_{\theta_{-i}, s}\left[\max _{\sigma_{i} \in\{0,1\}}\left[\left(v\left(\theta_{i}, s\right)+w-y_{i}\left(\hat{\theta}_{i}, \theta_{-i}\right)\right) \sigma_{i}\right] P_{i}\left(\hat{\theta}_{i}, \theta_{-i}\right)\right] \\
& +E_{\theta_{-i}}\left[\max \left\{w-z_{i}\left(\hat{\theta}_{i}, \theta_{-i}\right), 0\right\}\left(1-P_{i}\left(\hat{\theta}, \theta_{-i}\right)\right)\right],
\end{aligned}
$$

where $E_{\theta_{-i}}$ is the expectation over $\theta_{-i}$. We can then apply the envelope theorem (e.g., Milgrom and Segal (2002, corollary 1)) to obtain

$U_{i}\left(\theta_{i}, \theta_{i}\right)=E_{\theta_{-i}}\left[\int_{\underline{\theta}}^{\theta_{i}} E_{s}\left[\frac{\partial}{\partial \theta_{i}} v(\alpha, s) \sigma_{i}^{*}\left(\alpha, \alpha, \theta_{-i}, s\right)\right] P_{i}\left(\alpha, \theta_{-i}\right) d \alpha\right]+U_{i}(\underline{\theta}, \underline{\theta})$,

where the optimal solvency decision is given by $\sigma_{i}^{*}\left(\theta_{i}, \hat{\theta}_{i}, \hat{\theta}_{-i}, s\right)=$ $\mathbf{1}_{v\left(\theta_{i}, s\right)+w-y_{i}\left(\hat{\theta}_{i}, \hat{\theta}_{-i}\right) \geq 0}$. Equation (5) says that agent $i$ receives rents when he is allocated the good and stays solvent. Utility under unlimited liability can be attained by setting $\sigma_{i}^{*}=1$ in equation (5).

DEFINITION 1 (Standard): An auction is standard if it gives the lowest type utility $w$ and awards the good to the agent with the highest signal, $\theta_{i}$.

Assume there is no reserve price. The FPA is then standard under (HR), while the SPA is always standard.

Lemma 1 (Insolvency Effect): For any standard auction, bidders' interim utilities decrease if there is an increase in the probability of bankruptcy $(\forall \theta)(\forall s)$. Hence, each bidder's interim utility is larger under unlimited liability than under limited liability.

Proof: For any standard auction, the lowest type receives utility $w$ and the good is awarded to the highest type. Using equation (5), a decrease in $\sigma_{i}^{*}\left(\theta_{i}, \theta_{i}, \theta_{-i}, s\right)(\forall \theta)(\forall s)$ therefore lowers utility. Q.E.D.

Intuitively, one can think of the limited liability auction as a bundle of two products. The first is the normal unlimited liability good; the second is a put option for the good in bad states of nature. High types value the first product most highly, while low types value the second product more. This negative correlation implies that a bundle reduces the asymmetry among the reservation valuations of the population and extracts more rents than selling the good alone.

Under limited liability, bidders can limit their downside loss by declaring bankruptcy after a particularly bad shock. Despite this option value, the 
Insolvency Effect states that the introduction of limited liability lowers utilities. It must therefore be the case that prices are higher under limited liability.

Proposition 2: For any standard auction, expected interim prices (i.e., promised payments) are higher under limited liability than unlimited liability.

Proof: See Appendix C.

\section{B. Revenue with Full Recovery}

Suppose bidder $i$ is awarded the good in the auction and goes bankrupt. The seller then recovers the wealth of the bankrupt bidder and some value from the bankrupt assets, $w+\bar{v}$.

Definition 2 (Full Recovery): The auction satisfies full recovery if $\bar{v}=v\left(\theta_{i}, s\right)$.

This full-recovery condition is particularly important since it is the standing assumption of most models in the literature, including Rhodes-Kropf and Viswanathan (2000, 2005), Zheng (2001), DeMarzo et al. (2005), and the "strong seller" case of Waehrer (1995). This scenario therefore serves as a useful benchmark. The full-recovery assumption immediately leads to the following two results, the first of which is a restatement of results in the literature.

First, for any standard auction, an increase in the probability of bankruptcy, for all types of agents, leads to an increase in revenue. That is, the seller is bankruptcy loving. To see this observe that revenue equals welfare minus bidders' utilities. Raising the probability of bankruptcy has no effect on welfare, due to full recovery, but reduces rents, via the Insolvency Effect (Lemma 1), and thus raises revenue. This result has two corollaries.

(a) For all standard auctions, revenue is higher under limited liability than under unlimited liability. In the case of the FPA this is shown by RhodesKropf and Viswanathan (2000, corollary 2).

(b) A symmetric reduction in bidders' wealth in an FPA or SPA increases the seller's revenue. A reduction in wealth means bidders have less to lose, increasing bidders' aggressiveness and raising bankruptcy rates. This is shown by Waehrer (1995, proposition 4(a)).

The second result is that the SPA raises more revenue than the FPA. Under full recovery, welfare is independent of the bankruptcy rate and therefore constant across all standard auctions. Utilities are lower under the SPA than the FPA (Proposition 1(b)), so revenue is higher under the SPA than the FPA.

We have therefore shown that under full recovery, the seller is bankruptcy loving and prefers the SPA over the FPA. These results have an extreme implication: The seller's revenue is maximized by a stochastic SPA that induces bankruptcy with probability $1-\epsilon$, where $\epsilon$ is arbitrarily small. The auction works as follows. Bidder $i$ bids $B\left(\theta_{i}\right)$. With probability $\epsilon$, the winning bidder pays the second highest bid and is given a bonus of $\frac{1-\epsilon}{\epsilon} w$, in addition to the 
good itself; with probability $1-\epsilon$, the winner makes a very large supplemental payment. Thus, the bidder stays solvent with probability $E_{\theta_{-i}, s}\left[\sigma_{i}^{*}\right] \leq \epsilon$ and the seller fully extracts the bidders' rents. ${ }^{12}$

Full recovery implies that the seller is bankruptcy loving and would therefore like to choose an auction with a very high probability of insolvency. Since these auctions do not seem to be particularly prevalent, one is led to question the full-recovery assumption. The next two sections analyze this problem in two different ways. Section IV allows for an exogenously specified bankruptcy cost. This has the appealing feature that bidding behavior is the same as under full recovery. Section V endogenizes the recovery rate by allowing the seller to resell any bankrupt assets among the losers of the initial auction.

\section{Auctions with Exogenous Recovery}

This section analyzes costly bankruptcy, where the recovery rate, $\bar{v}\left(\theta_{i}, s\right) \leq$ $v\left(\theta_{i}, s\right)$, depends on the winner's type and the shock. For example, one can think of the seller taking over the winning bidder's company, albeit with some efficiency loss.

The cost of bankruptcy may be quite substantial. For example, White (1989) reports that, on average, the administrative cost of liquidation is around $21 \%$ of the amount paid to creditors. However, as suggested by the examples in the Introduction, the cost of bankruptcy can vary greatly across different cases. In this section we show that the seller's view of bankruptcy critically depends on whether this recovery rate is "large" or "small." In Section IV.B, we examine the large-recovery case, generalizing the full-recovery results. That is, the seller is bankruptcy loving and prefers the SPA to the FPA. In Section IV.C, we consider the small-recovery case, showing that the full-recovery results are completely reversed. That is, the seller is bankruptcy averse and prefers the FPA to the SPA. These results highlight the importance of the recovery rate and show that any seller should give serious thought to bankruptcy costs before designing an auction.

Before analyzing revenue, one should first note that since a bidder has only one chance to win the good, bidding behavior is identical to that in Section III.

\section{A. Deriving Revenue}

We assume that the seller has a low valuation, so does not set a reserve price, and that $\bar{v}\left(\theta_{i}, s\right)$ is increasing in $\theta_{i}$. Welfare under limited liability is given by

$$
E_{\theta, s}\left[\sum_{i} P_{i}(\theta)\left[\left(v\left(\theta_{i}, s\right)-\bar{v}\left(\theta_{i}, s\right)\right) \sigma_{i}^{*}+\bar{v}\left(\theta_{i}, s\right)\right]\right]+\sum_{i} w,
$$

\footnotetext{
${ }^{12}$ The bidding function obeys $E_{s}\left[\max \left\{v\left(\theta_{i}, s\right)+w / \epsilon-B\left(\theta_{i}\right), 0\right\}\right] \epsilon=w$. The bonus of $(1-\epsilon) w / \epsilon$ means that the agent bids as if he has wealth $w / \epsilon$ and ensures that bids are positive. Thus, $B\left(\theta_{i}\right) \rightarrow E_{s}\left[v\left(\theta_{i}, s\right)\right]$ as $\epsilon \rightarrow 0$.
} 
where the solvency decision $\sigma_{i}^{*} \in\{0,1\}$ maximizes bidder $i$ 's utility (4). Integrating interim utility (5) by parts, the ex ante expected utility of bidder $i$ is

$$
\boldsymbol{E}_{\theta}\left[\boldsymbol{U}_{i}\left(\theta_{i}, \theta_{i}\right)\right]=\boldsymbol{E}_{\theta, s}\left[P_{i}(\theta) \sigma_{i}^{*} \frac{\partial v\left(\theta_{i}, s\right)}{\partial \theta_{i}} \frac{1-F\left(\theta_{i}\right)}{f\left(\theta_{i}\right)}\right]+U_{i}(\underline{\theta}, \underline{\theta}) .
$$

Revenue equals welfare (6) minus bidders' utilities (7),

$$
E_{\theta, s}\left[\sum_{i} P_{i}(\theta)\left[\left(M R\left(\theta_{i}, s\right)-\bar{v}\left(\theta_{i}, s\right)\right) \sigma_{i}^{*}+\bar{v}\left(\theta_{i}, s\right)\right]\right]+\sum_{i}\left[w-U_{i}(\underline{\theta}, \underline{\theta})\right],
$$

where

$$
M R\left(\theta_{i}, s\right):=v\left(\theta_{i}, s\right)-\frac{\partial v\left(\theta_{i}, s\right)}{\partial \theta_{i}} \frac{1-F\left(\theta_{i}\right)}{f\left(\theta_{i}\right)}
$$

is analogous to a monopolist's marginal revenue (Bulow and Roberts (1989)). Equation (8) coincides with revenue under unlimited liability if $\sigma_{i}^{*}=1$. The usual monotonicity assumption is then given by

Assumption (MON): $M R\left(\theta_{i}, s\right)$ increases in $\theta_{i}(\forall s)$.

Under unlimited liability and (MON), revenue is maximized by any standard auction as in Myerson (1981). Under limited liability, the payment function $y_{i}(\theta)$ affects revenue through the solvency decision $\sigma_{i}^{*}$, so we will not generally be able to solve for the revenue-maximizing auction. ${ }^{13}$ Instead, we will use revenue (8) to compare classes of auctions.

\section{B. Revenue Maximization: Large Recovery}

We first generalize the full-recovery results in Section III.B by assuming that bankruptcy is followed by large recovery.

Definition 3 (Large Recovery): The auction satisfies large recovery if $\bar{v}\left(\theta_{i}, s\right) \geq$ $\operatorname{MR}\left(\theta_{i}, s\right)$.

One should notice that large recovery allows sizeable efficiency losses when $\theta_{i}$ is small, but is far more stringent when $\theta_{i}$ is large since $\lim _{\theta_{i} \rightarrow \bar{\theta}} v\left(\theta_{i}, s\right)-$ $M R\left(\theta_{i}, s\right)=0$ for most common distributions. Thus, the large-recovery assumption is relatively unlikely to hold when there are a large number of bidders. One can also get a sense of the size of the efficiency loss allowed by noting that $E_{\theta}\left[M R\left(\theta_{(1)}, s\right)\right]=E_{\theta}\left[v\left(\theta_{(2)}, s\right)\right]$. We can now state the parallel results to our findings under full recovery.

First, for any standard auction, an increase in the probability of bankruptcy, for all types of agents, leads to an increase in revenue. That is, the seller is

\footnotetext{
${ }^{13}$ The seller's complete revenue-maximization problem is to choose $\left\langle P_{i}, y_{i}, z_{i}\right\rangle$ to maximize revenue (8) subject to: (a) the bidder choosing $\sigma_{i}^{*}$ to maximize utility (4); (b) incentive compatibility; (c) individual rationality, $U_{i}(\underline{\theta}, \underline{\theta}) \geq w$; (d) $z_{i}(\theta) \leq w$; and (e) $\sum_{i} P(\theta)=1$.
} 
bankruptcy loving. This follows from the fact that, under large recovery, equation (8) is decreasing in the solvency rate $\sigma_{i}^{*}$. Intuitively, raising bankruptcy rates reduces rents through the Insolvency Effect, but has little impact on welfare. This result means that (a) for any standard auction, revenue is higher under limited liability than under unlimited liability, and (b) a symmetric reduction in wealth in an FPA or SPA increases revenue.

Second, the SPA raises more revenue than the FPA in the uniform-additive model where $v\left(\theta_{i}, s\right)=\theta_{i}-s, \bar{v}\left(\theta_{i}, s\right)=\bar{v}\left(\theta_{i}\right)-s$, and $s \sim U[0,1]$. To see this, notice that under the additivity assumption, revenue (8) becomes

$$
E_{\theta}\left[\left(M R\left(\theta_{i}\right)-\bar{v}\left(\theta_{i}\right)\right) E_{s}\left[\sigma_{i}^{*}\right]+E_{s}\left[\bar{v}\left(\theta_{i}, s\right)\right] \mid \theta_{i}=\theta_{(1)}\right],
$$

where $M R\left(\theta_{i}\right):=\theta_{i}-\left[1-F\left(\theta_{i}\right)\right] / f\left(\theta_{i}\right)$. When $s \sim U[0,1]$, Proposition 1(c) and footnote 9 imply that the interim solvency rate is higher under the FPA than under the SPA, $E_{\theta_{-i}, s}\left[\sigma_{i, \mathrm{FP}}^{*}\right] \geq E_{\theta_{-i}, s}\left[\sigma_{i, \mathrm{SP}}^{*}\right]$. The revenue ranking immediately follows.

Third, the seller's revenue is maximized by a stochastic auction that induces bankruptcy with probability $1-\epsilon$, as in Section III.B. This follows from the fact that the seller is bankruptcy loving. Therefore, just as under full recovery, we have the unappealing conclusion that the seller wishes to maximize the probability of bankruptcy, a result that is somewhat at odds with practical experience.

\section{Revenue Maximization: Small Recovery}

If the loss from bankruptcy is sufficiently large, then we reverse the largerecovery results.

Definition 4 (Small Recovery): The auction satisfies small recovery if $\bar{v}\left(\theta_{i}, s\right) \leq$ $M R\left(\theta_{i}, s\right)$.

First, for any standard auction, an increase in the probability of bankruptcy, for all types of agents, leads to a decrease in revenue. That is, the seller is bankruptcy averse. This follows from the fact that, under small recovery, equation (8) is increasing in the solvency rate $\sigma_{i}^{*}$. Intuitively, when the recovery rate is sufficiently small, the loss from bankruptcy outweighs the Insolvency Effect. This result means that (a) for any standard auction, revenue is lower under limited liability than under unlimited liability, and (b) a symmetric reduction in wealth in an FPA or SPA decreases revenue.

Second, the SPA raises less revenue than the FPA in the uniform-additive model where $v\left(\theta_{i}, s\right)=\theta_{i}-s, \bar{v}\left(\theta_{i}, s\right)=\bar{v}\left(\theta_{i}\right)-s$, and $s \sim U[0,1]$. This follows from equation (9). As shown in Proposition 1(a), the SPA yields higher prices than the FPA. However, a higher price is only useful if the money can be collected. Under small recovery, the beneficial effect of higher prices in the SPA is overwhelmed by the negative effect of higher bankruptcy rates.

We should note that while the FPA often yields higher revenue than the SPA, a standard auction may not be optimal if bankruptcy is sufficiently costly. 
Instead, the auctioneer may wish to (a) reduce the number of bidders or (b) give some surplus to the lowest type, effectively increasing all bidders' wealth.

We have therefore shown that the recovery rate assumption is crucial in determining the seller's preferences over the auction format. Under large recovery, the seller is bankruptcy loving and prefers the SPA. However, under small recovery, the seller is bankruptcy averse and prefers the FPA.

\section{Discussion: Credibility and Liquidation}

This paper has so far considered debt contracts where the price $y_{i}(\theta)$ is independent of the shock $s$. The motivation is straightforward: Since the shock is privately known by the winning bidder, any deterministic contract must take the form of a debt contract. Intuitively, the seller cannot forgive the debt of an insolvent bidder without also forgiving the debt of a perfectly solvent bidder, since the solvent bidder can always pretend to be insolvent. ${ }^{14}$

We have also assumed that the seller can commit to liquidate bidders who do not pay their bid in full. This degree of commitment seems reasonable if the seller cares about her reputation or if she can delegate the decision to pull the plug to a third party. Nevertheless, since bankruptcy is costly, the question remains whether such a liquidation decision is credible in the absence of such commitment devices.

To illustrate the credibility problem, suppose the seller uses an auction format that reveals the signal of the winning bidder, such as the FPA or the SPA, and denote the auction price by $y_{i}(\theta)$. After the auction, the winning bidder sees the shock $s$ and offers a payment $\rho$ to the seller. If the seller commits to liquidating any bidder who offers less than $y_{i}(\theta)$, then it is a weakly dominant strategy for an insolvent bidder to offer everything they have, that is, $\rho=\min \left\{y_{i}(\theta), v\left(\theta_{i}, s\right)+\right.$ $w$ \}. The problem is that the seller's liquidation strategy is not credible as she is always better off accepting $\rho$ instead of liquidating the bidder and receiving $\bar{v}\left(\theta_{i}, s\right)+w<v\left(\theta_{i}, s\right)+w$.

The seller can enhance her credibility by only allowing the winning bidder to make one of two possible offers: $y_{i}(\theta)$ and $v\left(\theta_{i}, \underline{s}\right)+w$. This contract can be interpreted as restricting the bidder to announce that they are either "solvent" or "insolvent," respectively. Since the seller does not observe the state $s$, she does not know how much she would receive from liquidation. The seller can thus credibly reject the offer of $v\left(\theta_{i}, \underline{s}\right)+w$ and liquidate the assets if

$$
E_{s}\left[\bar{v}\left(\theta_{i}, s\right) \mid v\left(\theta_{i}, s\right)+w-y_{i}(\theta)<0\right] \geq v\left(\theta_{i}, \underline{s}\right) .
$$

If bidders are not restricted in the offers they make to the seller, then a signaling equilibrium exists that looks similar to the "restricted offer" contract. In this equilibrium the bidders use the following strategy:

\footnotetext{
${ }^{14}$ More precisely, suppose the bidder reports a shock $\hat{s}$ to the seller, who chooses the payment $y_{i}(\hat{\theta}, \hat{s})$ and the bankruptcy decision $\sigma(\hat{\theta}, \hat{s}) \in\{0,1\}$. Then, in any incentive compatible mechanism, the payment of a solvent bidder cannot depend on $\hat{s}$, that is, $y_{i}(\hat{\theta}, \hat{s})=y_{i}(\hat{\theta})$ when $\sigma(\hat{\theta}, \hat{s})=1$. Moreover, a bidder will enter bankruptcy if and only if $v\left(\theta_{i}, s\right)+w<y_{i}(\hat{\theta})$. Hence, the only incentive compatible deterministic contract is a debt contract.
} 


$$
\rho= \begin{cases}y_{i}(\theta) & \text { if } v\left(\theta_{i}, s\right)+w-y_{i}(\theta) \geq 0 \\ v\left(\theta_{i}, \underline{s}\right)+w & \text { otherwise. }\end{cases}
$$

The seller's beliefs are as follows. If the bidder offers $\rho \in\left\{y_{i}(\theta), v\left(\theta_{i}, \underline{s}\right)+w\right\}$ then the seller's beliefs about $s$ are given by Bayes's rule. If the bidder makes any other offer, the seller believes the bidder has shock $\bar{s}$. The seller can credibly reject the offer $\rho=v\left(\theta_{i}, \underline{s}\right)+w$ and liquidate the assets if (10) holds. The seller can credibly reject any offer $\rho \in\left(v\left(\theta_{i}, \underline{s}\right)+w, y_{i}(\theta)\right)$ and liquidate the assets if

$$
\bar{v}\left(\theta_{i}, \bar{s}\right)+w \geq y_{i}(\theta) .
$$

Hence, the liquidation decision is credible if $\bar{v}\left(\theta_{i}, s\right)$ satisfies (10) and (11). These conditions hold if the range of $s$ is sufficiently large.

\section{Endogenous Recovery: Post-bankruptcy Resale}

This section endogenizes the recovery rate by assuming that the assets of a bankrupt firm are auctioned among the losing bidders of the initial auction.

The setup is as follows. The seller first sells the good to one of $N \geq 3$ bidders using an auction such as a FPA or SPA. The winning bidder then sees the common shock $s$ and decides whether or not to declare bankruptcy. If the winning bidder enters bankruptcy, the shock $s$ is publicly revealed and the good is sold using the same auction format among the $N-1$ losing bidders. ${ }^{15}$

Sections V.A and V.B analyze bidding behavior in FPA and SPAs taking into account that a bidder who wins the initial auction loses the ability to compete in the resale auction. Section V.C compares revenue and solvency rates across the different auction formats.

First, we show that with endogenous recovery the auctioneer is bankruptcy averse.

Proposition 3: Suppose bankruptcy is followed by resale and (MON) holds. Then revenue is higher under unlimited liability than limited liability for any standard auction.

\section{Proof: See Appendix D.}

Under limited liability, a standard auction allocates the good to the bidder with the highest value. With probability $1-\sigma_{i}^{*}$, the winner goes bankrupt and the seller reallocates the good to the bidder with the second highest value. This is isomorphic to a random auction that awards the good to the highest bidder with probability $\sigma_{i}^{*}$ and awards the good to the second highest bidder with probability $1-\sigma_{i}^{*}$. However, under (MON), revenue is maximized by a

\footnotetext{
${ }^{15}$ The assumption that the shock is identical across agents and publicly revealed after the first auction means that there can be only one round of bankruptcy. This substantially simplifies the derivation of bidding behavior.
} 
deterministic auction that awards the good to the highest bidder with probability one (Myerson (1981)).

\section{A. First-Price Auction}

Suppose the seller holds sequential FPAs in both the initial auction and any post-bankruptcy resale auction. We focus on symmetric equilibria where agents bid using strictly increasing and differentiable bidding strategies, $b\left(\theta_{i}\right)$. Assume that after the first auction the winning bid is revealed, but not the losing bids. ${ }^{16}$

First, consider the resale auction. For bidder $i$, let $\left(X_{1}, \ldots, X_{N-1}\right)$ denote the order statistics of his opponents' types. If bidder $i$ loses the initial auction, then, in equilibrium, the good will be won by the bidder with value $X_{1}$. Hence, in the resale auction, bidder $i$ believes that his opponents have types distributed on $\left[\theta, X_{1}\right]$. By revenue equivalence, bidder $i$ 's utility from this auction is then $E_{X_{2}}\left[\left(v\left(\theta_{i}, s\right)-v\left(X_{2}, s\right)\right) \mathbf{1}_{\theta_{i} \geq X_{2}} \mid X_{1}\right]$.

Now consider the initial auction. If bidder $i$ pretends to be type $\hat{\theta}_{i}$, he obtains

$$
\begin{aligned}
U\left(\theta_{i}, \hat{\theta}_{i}\right)= & w+E_{s}\left[\max \left\{v\left(\theta_{i}, s\right)+w-b\left(\hat{\theta}_{i}\right), 0\right\}-w\right] F_{1}\left(\hat{\theta}_{i}\right) \\
& +E_{s} \int_{\hat{\theta}_{i}}^{\infty} \mathbf{1}_{v\left(X_{1}, s\right)+w-b\left(X_{1}\right)<0} E_{X_{2}}\left[\mathbf{1}_{\theta_{i} \geq X_{2}}\left(v\left(\theta_{i}, s\right)-v\left(X_{2}, s\right)\right) \mid X_{1}\right] d F_{1}\left(X_{1}\right)
\end{aligned}
$$

where $F_{1}\left(\theta_{i}\right):=F^{N-1}\left(\theta_{i}\right)$. The first-order condition with respect to $\hat{\theta}_{i}$, evaluated at $\hat{\theta}_{i}=\theta_{i}$, is

$$
\begin{aligned}
& b^{\prime}\left(\theta_{i}\right) E_{s}\left[\mathbf{1}_{v\left(\theta_{i}, s\right)+w-b\left(\theta_{i}\right) \geq 0}\right] F_{1}\left(\theta_{i}\right) \\
& \quad=E_{s}\left[\mathbf{1}_{v\left(\theta_{i}, s\right)+w-b\left(\theta_{i}\right) \geq 0}\left[v\left(\theta_{i}, s\right)+w-b\left(\theta_{i}\right)+\phi\left(\theta_{i}, s\right)\right]-w-\phi\left(\theta_{i}, s\right)\right] F_{1}^{\prime}\left(\theta_{i}\right),
\end{aligned}
$$

where the expected utility from the resale auction, conditional on winning, is given by $\phi\left(\theta_{i}, s\right):=E_{X_{2}}\left[v\left(\theta_{i}, s\right)-v\left(X_{2}, s\right) \mid \theta_{i}>X_{2}\right]$. The boundary condition then states that $b(\underline{\theta})=\beta(\underline{\theta})$, where $\beta\left(\theta_{i}\right)$ is defined by

$$
E_{s}\left[\mathbf{1}_{v\left(\theta_{i}, s\right)+w-\beta\left(\theta_{i}\right) \geq 0}\left[v\left(\theta_{i}, s\right)+w-\beta\left(\theta_{i}\right)+\phi\left(\theta_{i}, s\right)\right]-w-\phi\left(\theta_{i}, s\right)\right]=0 .
$$

Resale lowers bids in the initial auction by raising the opportunity cost of winning. The opportunity cost, $\phi\left(\theta_{i}, s\right)$, appears in both the boundary condition (13) and the first-order condition (12), but is only paid in bad states of the world, when agent $i$ is insolvent. Intuitively, there is no opportunity cost in the good states since any bidder who beats agent $i$ will also remain solvent, preventing a resale auction. ${ }^{17}$

\footnotetext{
${ }^{16}$ Bidding in the resale auction is actually independent of whether or not the winner's bid is revealed (Milgrom and Weber (2000)).

${ }^{17}$ We initially assumed that the bidding function is monotone. Even with (HR), this may not be the case if the opportunity $\operatorname{cost} \phi\left(\theta_{i}, s\right)$ increases quickly in $\theta_{i}$ and the probability of bankruptcy is high. One can derive a sufficient condition for monotonicity using the approach of Maskin and Riley (1984, theorem 2).
} 


\section{B. Second-Price Auction}

Next, suppose the auctioneer holds sequential SPAs in both the initial auction and any post-bankruptcy resale auction. In the resale auction, it is a weakly dominant strategy for agent $i$ to bid $v\left(\theta_{i}, s\right)$. Hence, $i$ 's utility is again $E_{X_{2}}\left[\left(v\left(\theta_{i}, s\right)-v\left(X_{2}, s\right)\right) \mathbf{1}_{\theta_{i} \geq X_{2}} \mid X_{1}\right]$.

In the initial auction, suppose that bidders use strictly increasing, differentiable bidding strategies, $B\left(\theta_{i}\right)$. If agent $i$ pretends to be type $\hat{\theta}_{i}$, he obtains

$$
\begin{aligned}
U\left(\theta_{i}, \hat{\theta}_{i}\right)= & w+E_{s} \int_{\underline{\theta}}^{\hat{\theta}_{i}}\left[\max \left\{v\left(\theta_{i}, s\right)+w-B\left(X_{1}\right), 0\right\}-w\right] d F_{1}\left(X_{1}\right) \\
& +\int_{\hat{\theta}_{i}}^{\infty} E_{s, X_{2}}\left[\mathbf { 1 } _ { v ( X _ { 1 } , s ) + w - \operatorname { m a x } \{ B ( \hat { \theta } _ { i } ) , B ( X _ { 2 } ) \} < 0 } \mathbf { 1 } _ { \theta _ { i } \geq X _ { 2 } } \left(v\left(\theta_{i}, s\right)\right.\right. \\
& \left.\left.-v\left(X_{2}, s\right)\right) \mid X_{1}\right] d F_{1}\left(X_{1}\right) .
\end{aligned}
$$

The first-order condition with respect to $\hat{\theta}_{i}$, evaluated at $\hat{\theta}_{i}=\theta_{i}$, is

$$
\begin{aligned}
0= & E_{s}\left[\mathbf{1}_{v\left(\theta_{i}, s\right)+w-B\left(\theta_{i}\right) \geq 0}\left[v\left(\theta_{i}, s\right)+w-B\left(\theta_{i}\right)+\phi\left(\theta_{i}, s\right)\right]-w-\phi\left(\theta_{i}, s\right)\right] F_{1}^{\prime}\left(\theta_{i}\right) \\
& +\left.\frac{d}{d \hat{\theta}_{i}}\right|_{\hat{\theta}_{i}=\theta_{i}} \int_{\theta_{i}}^{\infty} E_{X_{2}, s}\left[\mathbf{1}_{v\left(X_{1}, s\right)+w-B\left(\hat{\theta}_{i}\right)<0} \mathbf{1}_{\theta_{i} \geq X_{2}}\left(v\left(\theta_{i}, s\right)-v\left(X_{2}, s\right)\right) \mid X_{1}\right] d F_{1}\left(X_{1}\right),
\end{aligned}
$$

where the boundary conditions are given by $B(\underline{\theta})=\beta(\underline{\theta})$ and $B(\bar{\theta})=\beta(\bar{\theta})$, with $\beta(\cdot)$ defined by equation (13).

There are two components to the second-price bidding strategy. An agent who ignores the second term would bid so that he is indifferent between winning and losing the auction when he just wins. Such an agent would bid according to $\beta\left(\theta_{i}\right)$, which differs from the bidding strategy without resale only in the opportunity cost term, $\phi\left(\theta_{i}, s\right)$.

Bidding is also determined by a "bankrupt your opponent" effect, which is captured by the second term. If agent $i$ thinks he is likely to come in second then he can increase his bid to raise the liability of the winner and increase the probability of bankruptcy. Note that this effect occurs in the SPA, but not the FPA, because the agent setting the price also stands to gain from bankruptcy in the first round. The highest type always wins the initial auction, so that $B(\bar{\theta})=\beta(\bar{\theta})$. On the other hand, the lowest type always loses the resale auction, so that $B(\underline{\theta})=\beta(\underline{\theta})$. Thus, the bankrupt your opponent effect raises bidding aggressiveness most for middling types.

The bankrupt your opponent effect may help explain a puzzling feature of the German 3G spectrum auctions. ${ }^{18}$ The German government auctioned 12 blocks of spectrum from which bidders could create licenses of either two or three blocks. There were initially seven bidders, with Debitel dropping out at a price of $€ 350$ per capita. The six bidders could then have reduced their demands to two blocks each, carving up the market for a relatively low price. Instead,

\footnotetext{
${ }^{18}$ See Grimm, Riedel and Wolfstetter (2002), Klemperer (2004) and the Financial Times's "MobilCom deal with FranceTel" (15/11/02).
} 
Deutsche Telecom and Mannesmann-Vodafone pushed the price up to $€ 615$ per capita before accepting the same allocation they could have achieved at a much lower price. This presents a conundrum: Why bid an extra dollar at a low price, when one's opponents are unlikely to drop out, but refuse to bid an extra dollar at a high price, when one's opponents are likely to drop out? One explanation is that firms care about relative performance, perhaps due to managerial career concerns (Klemperer (2004, section 7.8)). Another possibility is that the two largest firms wanted to raise the price paid by their competitors in order to drive them into bankruptcy. Indeed, one bidder, MobilCom, narrowly escaped bankruptcy 2 years later and, after being rescued by France Telecom, soon closed its $3 \mathrm{G}$ business.

\section{Comparing Auction Formats}

Table III compares the outcomes of different auctions in the additive-uniform model, where $v\left(\theta_{i}, s\right)=\theta_{i}-s, \theta_{i} \sim U[0,1]$, and $s \sim U[0,1]$.

When compared to the results in Section III.A, the introduction of resale reduces prices and bankruptcy rates. This is because the introduction of resale raises the opportunity cost of winning the good in the initial auction.

Comparing auction formats, the SPA leads to higher prices and bankruptcy rates than the FPA, as in Section III.A. The seller is bankruptcy averse (Proposition 3), so it may seem surprising that the SPA yields higher revenue than the FPA. The reason is that while bankruptcy is more likely under the SPA, it tends to be less costly. Fixing $\theta_{(1)}$, a high $\theta_{(2)}$ raises the winner's liability and the probability of bankruptcy. However, when $\theta_{(2)}$ is high, the lost revenue, $M R\left(\theta_{(1)}\right)-M R\left(\theta_{(2)}\right)$, is small. In contrast, under the FPA, bankruptcy will often occur when $\theta_{(2)}$ is very low and the revenue loss is very high.

An increase in bidders' wealth raises the cost of bankruptcy, and so reduces bidding aggressiveness and bankruptcy rates. Since the seller is bankruptcy averse, such an increase in wealth also raises revenue. An increase in the

\section{Table III}

\section{First-Price and Second-Price Auctions with Resale}

This table compares the first- and second-price auctions with post-bankruptcy resale. This example uses the uniform-additive model where $i$ 's signal is $\theta_{i} \sim U[0,1]$, the post-auction shock is $s \sim U[0,1]$ and $i$ 's valuation is $v\left(\theta_{i}, s\right)=\theta_{i}-s$. The first column describes the number of bidders and their wealth. The second column shows expected revenue. The third column gives the expected probability of solvency. The fourth and final column shows the expected price in the initial auction, prior to any bankruptcy decision.

\begin{tabular}{|c|c|c|c|c|c|c|c|}
\hline \multicolumn{2}{|c|}{ Parameters } & \multicolumn{2}{|c|}{ Revenue $\times 100$} & \multicolumn{2}{|c|}{ Prob. Solvency } & \multicolumn{2}{|c|}{ Expected Price $\times 100$} \\
\hline No. of Bidders & Wealth & FPA & SPA & $\mathrm{FPA}(\%)$ & $\mathrm{SPA}(\%)$ & FPA & SPA \\
\hline 5 & $1 / 10$ & 7.9 & 9.5 & 72.9 & 69.5 & 20.4 & 23.7 \\
\hline 10 & $1 / 10$ & 24.9 & 25.8 & 61.8 & 60.4 & 39.1 & 40.6 \\
\hline 10 & $1 / 100$ & 21.8 & 22.5 & 44.9 & 43.2 & 47.0 & 48.7 \\
\hline
\end{tabular}


number of bidders raises the order statistics, $\left(\theta_{(1)}, \theta_{(2)}\right)$, as well as increasing bidding aggressiveness. Consequently, bankruptcy rates increase, but the extra bidders lead to an increase in revenue.

\section{Applications}

Sections II-V analyze bidding behavior and revenue under different postauction recovery scenarios. In this section, we turn to a number of practical problems faced by auction designers. For simplicity, we adopt the exogenous recovery model throughout.

\section{A. The Spinoff Problem}

Large firms often create subsidiaries to bid for a contract on their behalf. In this section we investigate how much wealth a parent will voluntarily choose to give to their subsidiary. We then examine the impact this choice has on the seller's revenue.

Consider the following spinoff game. There are $N$ wealthy firms who wish to bid for a contract in an SPA with exogenous recovery. Each firm simultaneously chooses to create a subsidiary with wealth $w_{i}$ to bid in the auction. A subsidiary inherits the valuation of its parent, but can declare bankruptcy independent of the original firm. Any profits return to the parent.

LEMMA 2: In an SPA with exogenous recovery, increasing bidder i's wealth by $\Delta w$ increases $i$ 's interim utility by less than $\Delta w$.

Proof: Denote the largest opposing bid by $B_{1}$, which has distribution function $F_{B_{1}}(\cdot)$. Agent $i$ 's utility is then

$$
\int_{0}^{B\left(\theta_{i}, w_{i}\right)} E_{s}\left[\max \left\{0, v\left(\theta_{i}, s\right)+w_{i}-B_{1}\right\}\right] d F_{B_{1}}\left(B_{1}\right)+\int_{B\left(\theta_{i}, w_{i}\right)}^{\infty} w_{i} d F_{B_{1}}\left(B_{1}\right)
$$

Using the envelope theorem, the derivative of utility with respect to $w_{i}$ is less than one. Q.E.D.

PRoposition 4: In the symmetric subgame perfect equilibrium of the spinoff game, all the subsidiaries have wealth $w_{i}=0$. Every firm is worse off under this spinoff equilibrium than if the parents bid in the auction directly. Moreover, under small recovery, the seller is also worse off under this spinoff equilibrium.

Proof: In the bidding stage, the unique symmetric Nash equilibrium is for agents to bid according to (2). In the first stage, it then is a weakly dominant strategy for any parent to choose $w_{i}=0$ for their subsidiary, by Lemma 2 . Since bankruptcy is higher under the spinoff equilibrium, the Insolvency Effect (Lemma 1) means that all firms are worse off. Similarly, under small recovery, the increase in bankruptcy lowers revenue (8). Q.E.D. 
Wealthier bidders have more to lose and bid less aggressively. Thus, wealth is a competitive disadvantage and each parent will choose to create an aggressive subsidiary with no wealth. However, this strategy exerts a negative externality on other bidders, leading to a prisoner's dilemma whereby all firms are better off if parents bid rather than their subsidiaries. Under small recovery, the introduction of subsidiaries also reduces revenue. In this situation, the seller should adopt a policy of banning such spinoffs or adopting minimum wealth requirements.

To provide a practical illustration of the spinoff problem, consider the ITV Digital example mentioned in the Introduction. In 1998, Carlton and Granada, Britain's two largest TV companies, formed ITV Digital, a legally separate joint venture. With nothing to lose, this subsidiary bid very aggressively for football rights. Then, when demand did not meet its optimistic expectations, ITV Digital went into bankruptcy, owing the Football League $£ 178 \mathrm{~m}$. In contrast, the Premier League had a "parent company guarantee" with Carlton and Granada, and recovered $£ 20 \mathrm{~m}$ owed to it by ITV Digital.

\section{B. Cost-Plus versus Fixed-Fee Contracts}

So far, we have assumed that the shock, $s$, is not observed by the seller and therefore cannot affect the price. Suppose instead that the shock $s$ is verifiable, so that the seller has the option to use a cost-plus contract. When will such a contract be desirable?

For simplicity, suppose that valuations are additive, $v\left(\theta_{i}, s\right)=\theta_{i}-s$. Two options available to the seller are:

- A fixed-price auction, where $i$ 's payment, $y_{i}(\hat{\theta})$, is determined solely by the bidders' declarations. This is identical to the limited liability auctions studied in Sections II-V.

- A cost-plus auction, where the bidder pays $y_{i}(\hat{\theta})-s$. In this case, the bidder is completely insured from post-auction uncertainty and will never declare bankruptcy. Hence, this auction is identical to an unlimited liability auction.

Under small recovery, the seller is bankruptcy averse so revenue is maximized by a cost-plus standard auction (e.g., an FPA or SPA). Under large recovery, the seller is bankruptcy loving and revenue is larger under a fixed-price standard auction than a cost-plus standard auction. As in Section IV.B, revenue is maximized by a stochastic fixed-price auction that induces bankruptcy with probability $1-\epsilon$.

\section{Insurance}

As in Section VI.B, continue to assume that the shock $s$ is contractible. However, suppose that the seller simply runs a fixed-price auction. Will bidders then wish to insure themselves by contracting on this shock with a financial intermediary? 
In particular, consider an SPA, where a bidder has the option to purchase insurance from a competitive market in order to protect himself against postauction risk. For simplicity, suppose that valuations are additive, $v\left(\theta_{i}, s\right)=$ $\theta_{i}-s$, so an actuarially fair insurance policy pays out $s$ in state $s$ and costs $E[s]$ to purchase.

First, consider the case where bidders purchase insurance before competing in the auction. The game consists of the following stages: (1) bidders simultaneously choose whether or not to acquire insurance; $(2)$ the bidders compete in an SPA; (3) if the winner is insured, he pays $E[s]$ to the insurance company; (4) the shock is revealed and the winning bidder pays the second highest bid or declares bankruptcy. In the symmetric subgame perfect equilibrium of this game, all bidders will choose not to purchase insurance in order to commit to bidding aggressively. Acquiring insurance suffers from the same prisoner's dilemma that characterized the spinoff problem: Every bidder would be better off if they all acquired insurance, but no bidder has an individual incentive to do so.

Next, consider the case where bidders have the option to purchase insurance after competing in the auction but before the post-bankruptcy shock is realized. Without insurance, a winning bidder pays $s$ when he stays solvent but does not have to pay when he goes bankrupt. Consequently, a bidder will never choose to purchase actuarially fair insurance because the possibility of bankruptcy makes him risk loving. This also means that even if a bidder buys insurance before the auction, then he will seek to cancel the contract after the auction.

In sum, bidders will be reluctant to purchase insurance both before and after the auction. They prefer not to purchase insurance before the auction to make themselves more competitive; they prefer not to purchase insurance after the auction because bankruptcy makes them risk loving. Nevertheless, all the bidders would be better off if the bidders committed to using insurance. In addition, under small recovery, the seller is also better off if bidders acquire insurance. This suggests that the British government should consider making insurance compulsory when supplying services through the Private Finance Initiative since individual bidders will be unlikely to purchase it voluntarily.

\section{Other Applications}

Revealing Information. Suppose the seller can commit to reveal information about the state $s$ before the auction, but cannot contract on this information. For example, the seller of a building contract could promise to reveal the content of their surveyor's report. Such a revelation strategy would turn the auction into one of unlimited liability, increasing the revenue of a bankruptcy-averse seller and increasing the utilities of the bidders.

Bankruptcy Rules. We have assumed that a bidder who declares bankruptcy gets a payoff of zero. Suppose that the bankruptcy also involves a socially wasteful, nonpecuniary cost of $\kappa \geq 0$ for the insolvent bidder. An increase in $\kappa$ makes bankruptcy more costly, lowers bids, raises the probability of solvency, and, via the Insolvency Effect, raises utilities. Under large recovery, the seller is 
bankruptcy loving so prefers the smallest possible nonpecuniary cost. Under small recovery, the seller is bankruptcy averse so may prefer a strictly positive nonpecuniary cost, despite it being socially wasteful.

All-Pay Auctions. The proof of Proposition 1 shows that, under exogenous recovery, the FPA induces higher utilities and solvency rates than any standard winner-pays auction (including the SPA as a special case). However, by making losing bidders pay, the APA leads to even higher solvency rates than the FPA. Hence, the APA yields higher utilities than the FPA, via the Insolvency Effect, and higher revenues under the small-recovery assumption. ${ }^{19}$ However, the APA has two significant problems: It is often impractical and it may bankrupt losing bidders, reducing competition in any resale auction.

Entry Fees versus Reservation Prices. Consider the exogenous recovery model where the seller runs an FPA with either (a) a reservation price, or (b) an entry fee, so that the same types of bidders participate under either scenario. By making losing bidders pay, the entry fee reduces the debt of the winning bidder and raises the probability of solvency, in a manner analogous to the APA. Hence, under small recovery, the seller prefers entry fees over reservation prices. ${ }^{20}$

\section{E. Case Study: The Timber Bubble}

We end this paper with a case study of the Pacific Northwest timber auctions. This example demonstrates that bankruptcy considerations can become the primary determinant of how agents bid for contracts. Moreover, it illustrates the applicability of the model in explaining bidders' seemingly paradoxical behavior.

Throughout the 1970s, the price of Pacific Northwest lumber steadily increased. At the end of the decade, demand started to decline and then went into a free fall after the 1979 monetary contraction. Between 1978 and 1982, new orders for coastal lumber fell by one-third as interest rates rose and housing demand collapsed. Using a multisector macroeconomic model, Mattey (1990, p. 20) predicts that this should have led prices to halve between 1978 and 1981. In reality, bid prices doubled during this period.

While this price reaction may seem surprising, it is consistent with our model. After the 1979 Volcker disinflation, housing demand slumped and many timber firms edged toward bankruptcy. The level of uncertainty also increased, creating an environment in which speculation was rife, with one auction being won by a used car dealer (Mattey (1990, p. 37)). As predicted by our model, the decline in wealth and increase in uncertainty led bidding to become very aggressive. Mattey (1990, p. 32) quotes James Geisinger, a representative of one of the companies, as saying,

There are basically two ways to go out of business in our industry. One is to have no timber to process, and the other is to have timber that may be too costly to process.

\footnotetext{
${ }^{19}$ See Board (2005) for a proof.

${ }^{20}$ See Board (2005) for a proof.
} 
Mattey adds, "a company that purchased timber contracts at least had a chance of getting lucky." As bidding became more aggressive, the situation propagated itself, pushing firms further into the red. By 1981, widespread default was imminent.

Mattey's (1990, p. 39) firm-level regressions show that insolvent firms bid around $40 \%$ more than solvent firms. This led to significant allocative inefficiency, which grew worse as bankruptcy became more likely. Between 1979 and 1981, only 6 of the largest 17 firms increased their share of the market; of these 6,4 were insolvent (Mattey (1990, p. 43)). ${ }^{21}$

\section{Summary}

This paper analyzes limited liability auctions, examining bidding behavior and revenues in a world where bankruptcy is costly. The paper has two main contributions. First, we compare prices, utilities, and bankruptcy rates across different auction formats. Second, we analyze how different post-bankruptcy recovery rates affect the seller's view of bankruptcy and her preference over the auction format.

Sections III and IV analyze auctions with exogenous recovery. Examining bidding behavior, we show that prices are higher under the SPA than under the FPA. Consequently, bidders' utilities and solvency rates are lower under the SPA than under the FPA. The seller's preferences depend on the cost of bankruptcy: Under small recovery, the seller is bankruptcy averse and prefers the FPA; under large recovery, the seller is bankruptcy loving and prefers the SPA.

In Section V, we endogenize the degree of post-bankruptcy recovery, considering a model in which the auctioneer resells any bankrupt assets among the losing bidders from the initial auction. In the FPA, the introduction of resale dampens bidding by raising the opportunity cost of winning the initial auction. In the SPA, there is a second effect: Middling types bid more aggressively to bankrupt their opponents. Under resale recovery, the seller is bankruptcy averse but prefers the SPA to the FPA. Even though bankruptcy occurs more frequently under the SPA, bankruptcy will tend to occur when the efficiency loss is relatively small.

This analysis leads to a number of straightforward lessons for a bankruptcyaverse seller. First, the seller should use a cost-plus contract where possible (Section VI.B). Second, the seller should require bidders to purchase insurance where possible, since bidders are unlikely to purchase it voluntarily (Section VI.C). Third, the seller should adopt minimum wealth constraints or parent company guarantees when subsidiaries are bidding on a parent's behalf (Section VI.A). Fourth, the seller should adopt an FPA when she seeks to minimize

\footnotetext{
${ }^{21}$ This allocative inefficiency is also predicted by our model. In the exogenous recovery model, wealth asymmetry can result in allocative inefficiency as poorer bidders act more aggressively. Moreover, in an SPA, a symmetric reduction in all bidders' wealth will increase the degree of allocative inefficiency (Board (2005)).
} 
the probability of bankruptcy (Section IV.C), but may want to use an SPA if any bankrupt assets are going to be resold (Section V.C). While many of these suggestions seem quite practical, they only follow from a model in which bankruptcy is sufficiently costly. Therefore, perhaps the most important lesson for a seller is to consider which post-bankruptcy scenario is most likely before designing the auction.

\section{Appendix A: Existence of Equilibrium in First-Price Auctions}

LEMMA 3: Under (HR), there exists an increasing symmetric equilibrium in the first-price auction with exogenous recovery.

Proof: Athey (2001, theorem 7) and Maskin and Riley (1984, theorem 2) show that an increasing symmetric equilibrium exists if $u\left(\theta_{i}, w-b_{i}\right)-w$, as given by equation (1), is log-supermodular in $\left(\theta_{i}, b_{i}\right)$ for $b_{i} \leq B\left(\theta_{i}\right)$. Letting $x:=$ $w-b_{i}$ be net wealth, we need to show $u\left(\theta_{i}, x\right)-w$ is log-submodular in $\left(\theta_{i}, x\right)$ for $x \geq w-B\left(\theta_{i}\right)$. Taking the cross-partial, we thus wish to show

$$
\psi(x):=\left[u\left(\theta_{i}, x\right)-w\right] u_{x \theta_{i}}\left(\theta_{i}, x\right)-u_{\theta_{i}}\left(\theta_{i}, x\right) u_{x}\left(\theta_{i}, x\right)
$$

is negative for $x \geq w-B\left(\theta_{i}\right)$.

Let us consider the boundary point, where $x=w-B\left(\theta_{i}\right)$. By construction, $u\left(\theta_{i}, w-B\left(\theta_{i}\right)\right)-w=0$ so $\psi(x)=-u_{\theta_{i}}\left(\theta_{i}, x\right) u_{x}\left(\theta_{i}, x\right) \leq 0$. To prove that $\psi(x) \leq 0$ for $x>w-B\left(\theta_{i}\right)$, it is sufficient to show that $\psi(x)=0 \Rightarrow \psi^{\prime}(x) \leq 0$. Differentiating (A1),

$$
\psi^{\prime}(x):=\left[u\left(\theta_{i}, x\right)-w\right] u_{x x \theta_{i}}\left(\theta_{i}, x\right)-u_{\theta_{i}}\left(\theta_{i}, x\right) u_{x x}\left(\theta_{i}, x\right) .
$$

When $\psi(x)=0$, then $u\left(\theta_{i}, x\right)-w>0$ and $u_{x \theta_{i}}\left(\theta_{i}, x\right)>0$. Substituting for $u\left(\theta_{i}, x\right)-w$, we obtain

$$
\left.\psi^{\prime}(x)\right|_{\psi(x)=0} \stackrel{\operatorname{sgn}}{=} u_{\theta_{i}}\left(\theta_{i}, x\right)\left[u_{x}\left(\theta_{i}, x\right) u_{x x \theta_{i}}\left(\theta_{i}, x\right)-u_{x \theta_{i}}\left(\theta_{i}, x\right) u_{x x}\left(\theta_{i}, x\right)\right] .
$$

Assumption (HR) is equivalent to the log-submodularity of $u_{x}\left(\theta_{i}, x\right)$,

$$
\frac{d^{2}}{d \theta_{i} d x} \ln \left[u_{x}\left(\theta_{i}, x\right) \stackrel{\text { sgn }}{=} u_{x}\left(\theta_{i}, x\right) u_{x x \theta_{i}}\left(\theta_{i}, x\right)-u_{x \theta_{i}}\left(\theta_{i}, x\right) u_{x x}\left(\theta_{i}, x\right) \leq 0 .\right.
$$

Using equation (A2), (HR) thus implies that $\psi^{\prime}(x) \leq 0$ when $\psi(x)=0$, as required. Q.E.D.

\section{Appendix B: Proof of Proposition 1}

We prove a more general result than stated, comparing FPAs and standard winner-pays auctions (where the good is awarded to the bidder with the highest signal and only the winning bidder pays). This includes the SPA as a special case. 
The following result will prove useful. From equation (1), the utility of agent $i, u\left(\theta_{i}, x\right)$, is a function of his type $\theta_{i}$ and net wealth $x=w-y_{i}$. The coefficient of absolute risk aversion under limited liability is

$$
-\frac{u_{x x}\left(\theta_{i}, x\right)}{u_{x}\left(\theta_{i}, x\right)}=\frac{-g\left(-x \mid \theta_{i}\right)}{1-G\left(-x \mid \theta_{i}\right)}
$$

Hence, (HR) implies $-u_{x x}\left(\theta_{i}, x\right) / u_{x}\left(\theta_{i}, x\right)$ is increasing in $\theta_{i}$, which means an agent with a higher signal is less risk-loving. Suppose $\tilde{x}$ is a random variable while $x$ is fixed. We can thus apply lemma 1 of Maskin and Riley (1984), which says that if $-u_{x x}\left(\theta_{i}, x\right) / u_{x}\left(\theta_{i}, x\right)$ is increasing in $\theta_{i}$, then $u\left(\theta_{i}, x\right)=E_{\tilde{x}}\left[u\left(\theta_{i}, \tilde{x}\right)\right]$ implies $u_{\theta_{i}}\left(\theta_{i}, x\right) \geq E_{\tilde{x}}\left[u_{\theta_{i}}\left(\theta_{i}, \tilde{x}\right)\right]^{22}$

Utilities. Consider a standard winner-pays auction with payment $y_{i}(\theta)$ and suppose bidder $i$ pretends to be type $\hat{\theta}_{i}$. By the revelation principle, we can look for equilibria where all agents tell the truth. If $-i$ reveal truthfully then bidder $i$ 's utility is

$$
U_{\mathrm{wP}}\left(\theta_{i}, \hat{\theta}_{i}\right)=E_{\theta_{-i}}\left[\left[u\left(\theta_{i}, w-y_{i}\left(\hat{\theta}_{i}, \theta_{-i}\right)\right)-w\right] \mathbf{1}_{\hat{\theta}_{i}>\max _{j \neq i} \theta_{j}}\right]+w .
$$

Applying the envelope theorem, the utility under truth-telling, denoted $U_{\mathrm{wP}}\left(\theta_{i}\right)$, obeys

$$
U_{\mathrm{wP}}^{\prime}\left(\theta_{i}\right)=E_{\tilde{y}_{i}}\left[u_{\theta_{i}}\left(\theta_{i}, w-\tilde{y}_{i}\right)\right] F^{N-1}\left(\theta_{i}\right)
$$

where the random variable $\tilde{y}_{i}$ is bidder $i$ 's payment conditional on winning. Under the FPA, $\tilde{y}_{i}=b\left(\theta_{i}\right)$, and we have

$$
U_{\mathrm{FP}}^{\prime}\left(\theta_{i}\right)=u_{\theta_{i}}\left(\theta_{i}, w-b\left(\theta_{i}\right)\right) F^{N-1}\left(\theta_{i}\right)
$$

Lemma 1 of Maskin and Riley (1984) thus implies that $U_{\mathrm{FP}}^{\prime}\left(\theta_{i}\right) \geq U_{\mathrm{WP}}^{\prime}\left(\theta_{i}\right)$ when $U_{\mathrm{FP}}\left(\theta_{i}\right)=U_{\mathrm{WP}}\left(\theta_{i}\right)$. For the lowest type $U_{\mathrm{FP}}(\underline{\theta})=U_{\mathrm{WP}}(\underline{\theta})$, so $U_{\mathrm{FP}}\left(\theta_{i}\right) \geq U_{\mathrm{WP}}\left(\theta_{i}\right)\left(\forall \theta_{i}\right)$.

Prices. Suppose bidder $i$ wins and $b\left(\theta_{i}\right)>E_{\tilde{y}_{i}}\left[\tilde{y}_{i}\right]$. Applying Jensen's inequality,

$$
\begin{aligned}
E_{\tilde{y}_{i}, s}\left[\left(v\left(\theta_{i}, s\right)+w-\tilde{y}_{i}\right) \vee 0\right] F^{N-1}\left(\theta_{i}\right) & \geq E_{s}\left[\left(v\left(\theta_{i}, s\right)+w-E_{\tilde{y}_{i}}\left[\tilde{y}_{i}\right]\right) \vee 0\right] F^{N-1}\left(\theta_{i}\right) \\
& >E_{s}\left[\left(v\left(\theta_{i}, s\right)+w-b\left(\theta_{i}\right)\right) \vee 0\right] F^{N-1}\left(\theta_{i}\right) .
\end{aligned}
$$

where " $\vee$ " is the maximum operator. Hence, $U_{\mathrm{wP}}\left(\theta_{i}\right)>U_{\mathrm{FP}}\left(\theta_{i}\right)$, contradicting the above result.

\footnotetext{
${ }^{22}$ The approach behind the "utilities" part of this proof was first used by Matthews (1987). Assuming an increasing FPA bidding strategy exists, the result that the FPA yields lower prices than the SPA holds without the (HR) assumption, using a proof along the lines of Maskin and Riley (1984, theorem 4).
} 
Solvency. Since $b\left(\theta_{i}\right) \leq E_{\tilde{y}_{i}}\left[\tilde{y}_{i}\right]$ and $1-G\left(v \mid \theta_{i}\right)$ is concave in $v$, Jensen's inequality implies

$$
\begin{aligned}
\operatorname{Prob} \text { Solvency }(\mathrm{WP}) & =E_{\tilde{y}_{i}}\left[1-G\left(\tilde{y}_{i}-w \mid \theta_{i}\right)\right] \\
& \leq 1-G\left(E_{\tilde{y}_{i}}\left[\tilde{y}_{i}\right]-w \mid \theta_{i}\right) \\
& \leq 1-G\left(b\left(\theta_{i}\right)-w \mid \theta_{i}\right)=\text { Prob Solvency (FPA), }
\end{aligned}
$$

as required.

\section{Appendix C: Proof of Proposition 2}

For any standard auction, Lemma 1 implies utility is greater under unlimited liability than under limited liability. Hence,

$$
\begin{aligned}
& E_{\theta_{-i}}\left[E_{s}\left[\left(v\left(\theta_{i}, s\right)+w-y_{i}^{\mathrm{UL}}(\theta)\right)\right] P_{i}^{\mathrm{UL}}(\theta)+\left[w-z_{i}^{\mathrm{UL}}(\theta)\right]\left(1-P_{i}^{\mathrm{UL}}(\theta)\right)\right] \\
& \quad \geq E_{\theta_{-i}}\left[E_{s}\left[\left(v\left(\theta_{i}, s\right)+w-y_{i}(\theta)\right) \vee 0\right] P_{i}(\theta)+\left[\left(w-z_{i}(\theta)\right) \vee 0\right]\left(1-P_{i}(\theta)\right)\right] \\
& \quad \geq E_{\theta_{-i}}\left[E_{s}\left[\left(v\left(\theta_{i}, s\right)+w-y_{i}(\theta)\right)\right] P_{i}(\theta)+\left[w-z_{i}(\theta)\right]\left(1-P_{i}(\theta)\right)\right]
\end{aligned}
$$

where " $\vee$ " is the maximum operator. In two standard auctions, $P_{i}(\theta)=P_{i}^{\mathrm{UL}}(\theta)$, hence,

$$
E_{\theta_{-i}}\left[y_{i}(\theta) P_{i}(\theta)+z_{i}(\theta)\left(1-P_{i}(\theta)\right)\right] \geq E_{\theta_{-i}}\left[y_{i}^{\mathrm{UL}}(\theta) P_{i}(\theta)+z_{i}^{\mathrm{UL}}(\theta)\left(1-P_{i}(\theta)\right)\right] .
$$

Since $y_{i}(\theta)$ is the payment of the winner and $z_{i}(\theta)$ is that of the loser, equation (C1) says that agent $i$ promises to pay more under limited liability than under unlimited liability, as required.

\section{Appendix D: Proof of Proposition 3}

Suppose the seller chooses a reduced-form mechanism that depends upon the shock $s$ and bidders' declared types $\hat{\theta}$. The mechanism specifies: (1) the probability a bidder obtains the good and remains solvent, $P_{i}^{S}(\hat{\theta}, s) ;(2)$ the probability a bidder obtains the good and enters bankruptcy, $P_{i}^{B}(\hat{\theta}, s)$; and (3) the payment a bidder makes, $y_{i}(\hat{\theta}, s)$. If bidders $-i$ declare truthfully, bidder $i$ then declares $\hat{\theta}_{i}$ to maximize utility:

$$
\begin{aligned}
U_{i}\left(\theta_{i}, \hat{\theta}_{i}\right)= & E_{\theta_{-i}, s}\left[\left[v\left(\theta_{i}, s\right)+w\right] P_{i}^{S}\left(\hat{\theta}_{i}, \theta_{-i}, s\right)\right. \\
& \left.+w\left[1-P_{i}^{S}\left(\hat{\theta}_{i}, \theta_{-i}, s\right)-P_{i}^{B}\left(\hat{\theta}_{i}, \theta_{-i}, s\right)\right]-y\left(\hat{\theta}_{i}, \theta_{-i}, s\right)\right] .
\end{aligned}
$$

Using the envelope theorem, utility is

$$
U_{i}\left(\theta_{i}, \theta_{i}\right)=E_{\theta_{-i}, s}\left[\int_{\underline{\theta}}^{\theta_{i}}\left[\frac{\partial}{\partial \theta_{i}} v(\alpha, s)\right] P_{i}^{S}\left(\alpha, \theta_{-i}, s\right) d \alpha\right]+U_{i}(\underline{\theta}, \underline{\theta}) .
$$


As in the case without resale, we see that utility depends only upon the probability of obtaining the good and staying solvent. Revenue in this auction is

$$
E_{\theta, s}\left[\sum_{i} P_{i}^{S}(\theta, s) M R\left(\theta_{i}, s\right)\right]+\sum_{i}\left(w-U_{i}(\underline{\theta}, \underline{\theta})\right) .
$$

Under (MON), the revenue-maximizing auction gives the lowest type no surplus and awards the good to the bidder with the highest signal, as in a standard unlimited liability auction. Since the mechanism subsumes all limited liability auctions, a standard unlimited liability auction yields higher revenue than any limited liability auction, as required.

\section{REFERENCES}

Athey, Susan, 2001, Single crossing properties and the existence of pure strategy equilibria in games of incomplete information, Econometrica 69, 861-889.

Board, Simon, 2005, Bidding into the red: Web appendix, Working paper, University of Toronto, http://www.economics.utoronto.ca/board/papers/bankrupt-webappendix.pdf.

Bulow, Jeremy, Ming Huang, and Paul Klemperer, 1999, Toeholds and takeovers, Journal of Political Economy 107, 427-454.

Bulow, Jeremy, and John Roberts, 1989, The simple economics of optimal auctions, Journal of Political Economy 97, 1060-1090.

Burkart, Mike, 1995, Initial shareholdings and overbidding in takeover contests, Journal of Finance 50, 1491-1515.

Cramton, Peter, Robert Gibbons, and Paul Klemperer, 1987, Dissolving a partnership efficiently, Econometrica 55, 615-632.

DeMarzo, Peter, Ilan Kremer, and Andrzej Skrzypacz, 2005, Bidding with securities-auctions and security design, American Economic Review 95, 936-959.

Goeree, Jacob K., Emiel Maasland, Sander Onderstal, and John L. Turner, 2005, How (not) to raise money, Journal of Political Economy 113, 897-918.

Grimm, Veronkia, Frank Riedel, and Elmar Wolfstetter, 2002, The third generation (utms) spectrum auction in Germany, ifo Studien 48, 123-143.

Hansen, Robert G., and John R. Lott, 1991, The winner's curse and public information in common value auctions: Comment, American Economic Review 81, 347-361.

Hart, Oliver, and John Moore, 1994, A theory of debt based on the inalienability of human capital, Quarterly Journal of Economics 109, 841-879.

Hart, Oliver, and John Moore, 1998, Default and renegotiation: A dynamic model of debt, Quarterly Journal of Economics 113, 1-41.

Klemperer, Paul, 2004, Auctions: Theory and Practice (Princeton University Press, Princeton, New Jersey).

Maskin, Eric, and John Riley, 1984, Optimal auctions with risk averse buyers, Econometrica 52, 1473-1518.

Mattey, Joe P., 1990, The Timber Bubble that Burst: Government Policy and the Bailout of 1984 (Oxford University Press, New York).

Matthews, Steven A., 1987, Comparing auctions for risk averse buyers: A buyer's point of view, Econometrica 55, 633-646.

Milgrom, Paul, and Ilya Segal, 2002, Envelope theorems for arbitrary choice sets, Econometrica 70, 583-601.

Milgrom, Paul, and Robert Weber, 2000, A theory of auctions and competitive bidding-part ii, in Paul Klemperer, ed.: The Economic Theory of Auctions, Vol. II (Edward Elgar, Cheltenham, UK), 179-194.

Myerson, Roger, 1981, Optimal auction design, Mathematics of Operations Research 6, 58-73. 
Rhodes-Kropf, Matthew, and S. Viswanathan, 2000, Corporate reorganizations and non-cash auctions, Journal of Finance 55, 1807-1849.

Rhodes-Kropf, Matthew, and S. Viswanathan, 2005, Financing auction bids, RAND Journal of Economics 36, 789-815.

Shleifer, Andrei, and Robert W. Vishny, 1992, Liquidation values and debt capacity: A market equilibrium approach, Journal of Finance 47, 1343-1366.

Waehrer, Keith, 1995, A model of auction contracts with liquidated damages, Journal of Economic Theory 67, 531-555.

White, Michelle J., 1989, The corporate bankruptcy decision, Journal of Economic Perspectives 3, $129-151$.

Zheng, Charles, 2001, High bids and broke winners, Journal of Economic Theory 100, 129-171. 